\title{
Choice of baseline in a multiple-dose thorough QT study (TQTS) - effect on analysis of moxifloxacin-induced QTc prolongation
}

This article was published in the following Dove Press journal:

Open Access Journal of Clinical Trials

21 December 2009

Number of times this article has been viewed

B Tyl'

S Azzam²

E Reinbolt ${ }^{2}$

$N$ Blanco'

J Olbertz ${ }^{3}$

WWheeler'

'MDS Pharma Services, Centralized Cardiac Services, Baillet-en-France, France; ${ }^{2}$ MDS Pharma Services, Early Clinical Research, Lincoln (Nebraska), USA; ${ }^{3}$ MDS Pharma Services, Early Clinical Research, Phoenix (Arizona), USA
Correspondence: Benoît Tyl MDS Pharma Services, I-3, Avenue du Bosquet, 95560 Baillet en France Tel +33 I 34083864

Fax +3 I3408 3323

Email tyl@noos.fr
Background: The primary endpoint of a thorough QT study (TQTS) is the change from baseline in QT corrected (QTc) measured on electrocardiograms (ECG) tracings. It has been suggested that during a crossover study, the time-matched or predose baseline could be recorded. The choice of method for baseline ECG collection may influence the results and the cost of the TQTS.

Objective: The objective of our study was to compare the collection of a time-matched baseline before each period $\left(\mathrm{TM}_{\mathrm{EACH}}\right)$, an average of all the time-matched baseline $\left(\mathrm{TM}_{\mathrm{MEAN}}\right)$, a time-matched baseline before period $1\left(\mathrm{TM}_{\mathrm{P} 1}\right)$ and a predose baseline $\left(\mathrm{PD}_{\mathrm{EACH}}\right)$ on QT interval prolongation induced by moxifloxacin, in a 30 subjects, 5 arm cross-over TQTS.

Results: Moxifloxacin induced a similar significant increase in QT corrected using Fridericia's formula (QTc) (lower limit of the confidence interval excluded $5 \mathrm{~ms}$ ) at all time-points between 0.5 hours and 12 hours with all baseline methods. $\mathrm{TM}_{\mathrm{EACH}}$ was associated with a lower within subject variability (SD 5.59 ms) than $\mathrm{TM}_{\mathrm{MEAN}}$ and $\mathrm{TM}_{\mathrm{P} 1}\left(5.90\right.$ and $6.90 \mathrm{~ms}$, respectively). $\mathrm{PD}_{\mathrm{EACH}}$ was associated with the highest variability $(7.41 \mathrm{~ms})$.

Conclusion: The collection of ECG tracings during a full baseline day before each period was associated with the lowest variability. However, the two more cost effective designs $\left(\mathrm{TM}_{\mathrm{P} 1}\right.$ and $\mathrm{PD}_{\mathrm{EACH}}$ ) were sufficient, in this small TQTS, to significantly detect moxifloxacin.

Keywords: thorough QT study, QT correction, baseline, design, superimposed representative complex, moxifloxacin

\section{Introduction}

The ability of many drugs to delay cardiac repolarization leading to cardiac arrhythmias such as "Torsades de Pointes" and subsequent sudden death, has been a concern for over two decades. ${ }^{2-5}$ Consequently, the International Conference on Harmonization (ICH) Guidance E14 ${ }^{6}$ was issued in 2005 to provide recommendations on design, conduct, analysis, and interpretation of clinical studies for the assessment of proarrhythmic potential of non-antiarrhythmic drugs. It recommends conduct of a "thorough QT/QTc" study (TQTS) to measure the effect of a drug on the QT interval early in development to determine the need for intensive QT monitoring during later development. The TQTS compares the QT and heart-rate corrected QT (QTc) intervals of the study with the drug administered at therapeutic and supra-therapeutic doses compared to that of placebo after correction for baseline QT/QTc intervals. Additionally, to assess the sensitivity of the study, a drug known to increase the QT interval near the threshold of regulatory concern $(+5 \mathrm{~ms})$ should be used as a positive control. Because QT is highly variable, the primary end-point is defined as the upper limit of 
the one-sided $95 \%$ confidence interval (CI) of the maximum QT/QTc change.

Since the QT interval is affected by factors that might vary depending on the time of day, eg circadian rhythm ${ }^{7-9}$ food ingestion, ${ }^{10}$ physical activity, and postural changes, ${ }^{11}$ the guidance suggests the collection of electrocardiograms (ECGs) at multiple time points (at baseline and after dosing), and states that the effect of the drug on the QT/QTc interval "is most commonly analyzed using the largest time-matched mean difference between the drug and placebo (baselineadjusted) over the collection period". Several different methods for baseline collection have been proposed ${ }^{12}$ including time-matched methods (requiring a 24-hour baseline before each test period) and predose baseline (average of several predose time points). A predose baseline has been shown to be effective in single dose TQTS, ${ }^{13,14}$ although the impact of baseline methods in multiple dose TQTS could be different due to day-to-day QT variability.

\section{Methods}

\section{Subjects and study design}

This was a multiple-dose (once daily for 4 days), randomized, triple dummy, double-blind, 5-way crossover study (placebo control, active control of $400 \mathrm{mg}$ moxifloxacin, therapeutic and supra-therapeutic doses of study drug, and therapeutic study drug dose co-administered with a CYP P450 inhibitor). Blinding of moxifloxacin was ensured by over encapsulation. Thirty subjects were enrolled and 28 subjects completed the study which was conducted at MDS Pharma Services, Phoenix, Arizona in accordance with the Declaration of Helsinki and Good Clinical Practice.

Participants completed 5 confinement periods with a minimum 7-day washout between periods. For each period, subjects were admitted to the clinic at least 12 hours prior to the start of baseline ECG collections on Day 1 and remained confined until completion of events on Day 7.

Subjects were awakened at least 1 hour prior to the start of ECG collections and were not allowed to sleep during the day because the QT-RR relationship is different during sleep. ${ }^{15}$ The QT is also influenced by meals. ${ }^{10}$ therefore, subjects fasted for 8 hours prior to and 4 hours following each dosing, and during the same time interval on Day 1. No ECGs were recorded less than 1 hour after a meal.

\section{Timing, recording, and interpretation of ECGs}

Three 10-second digital ECG recordings were obtained within a 2-minute window using a GE Healthcare Mac 1200 device
(Milwaukee, Wisconsin, USA) at: Hour 0 (predose), 0.5, 1, $1.5,2,3,4,6,8,10,12,16$, and 24 on Day 1 and Day 4, Hours 36 and 48 (Day 5), and Hour 72 (Day 6).

Tracings were digitally transmitted to a central ECG laboratory (MDS PS Baillet-en-France, France) for interpretation. All ECG interval durations for each subject were measured semi-automatically on 12 superimposed representative complexes ${ }^{16}$ in a random order by the same cardiologist blinded to collection time and treatment, using Trace ${ }^{\circledR}$ (Cardionics, Brussels, Belgium) software. The software prepositioned the calipers that were then adjusted as needed by the cardiologist. Once the intervals were measured, the cardiologist performed a rhythm, morphology, and repolarization assessment. Discrete U waves were excluded from the QT/QTc interval measurement.

The mean RR interval of the 10 second tracing was used to obtain heart rate corrected QT intervals (Fridericia's correction; $\left.\mathrm{QTcF}=\mathrm{QT} /[\mathrm{RR}]^{1 / 3}\right) ;{ }^{17}$ The relation between $\mathrm{QT}$ and RR intervals has been shown to be highly individual among healthy subjects ${ }^{18}$ and the use of subject specific QT/RR corrections (QTcI) has been proposed for pharmacological studies. ${ }^{19}$ If the active drug is associated with a change in heart rate, the QTcI is superior to QTcF in correcting the QT interval for heart rate; if there is minimal change in heart rate, QTcF is sufficient. The calculation of a robust QTcI requires the recording of at least 50 to 100 off-treatment ECG tracings ${ }^{20}$ that can only be recorded during full baseline days making the predose method unsuitable. In our study, as no significant change in heart rate was noted (the maximum increase in HR during the first 12 hours was noted at one time point in the moxifloxacin group and did not exceed $4 \mathrm{bpm}$ ), the QTcF sufficiently corrected the QT interval for heart rate.

\section{Statistical analysis of QTC intervals}

\section{Baselines}

The 4 methods for measuring baseline QT/QTc intervals were: a) 24-hour, time-matched baseline from each period $\left(\mathrm{TM}_{\mathrm{EACH}}\right)$. b) 24-hour, time-matched baseline from the mean of all periods $\left(\mathrm{TM}_{\mathrm{MEAN}}\right)$. c) 24-hour, time-matched baseline from the first period only $\left(\mathrm{TM}_{\mathrm{P}}\right.$ ). d) Predose (Hour 0) value of each period as the baseline $\left(\mathrm{PD}_{\mathrm{EACH}}\right)$.

For each time point, the average of the triplicate QTcF intervals was calculated and recorded as the QTcF for that time point. The change from baseline in QTcF $(\Delta \mathrm{QTcF})$ on Day 4 was calculated for each subject with the three 24 hour, time-matched baselines $\left(\mathrm{TM}_{\mathrm{EACH}}, \mathrm{TM}_{\mathrm{MEAN}}\right.$ and $\left.\mathrm{TM}_{\mathrm{P1}}\right)$ using the QTcF at each time point on Day 4 and the QTcF at the corresponding time point on Day 1. 
The predose baseline was the QTcF at Hour 0 on Day 1 of each period. For each subject, the $\Delta \mathrm{QTcF}$ on Day 4 was calculated as the difference between the QTcF on Day 4 and the baseline value from the corresponding period. All four methods are described in Figure 1.

\section{Statistical model}

The $\triangle \mathrm{QTcF}$ values were subjected to an analysis of covariance (ANCOVA) for repeated measures, with each subject's baseline value $(\mathrm{BL})$ being the covariate. The model included factors for enrolment group, period, sequence, and treatment. Depending on the baseline scenario, BL was either each subject's time-matched baseline value or each subject's predose baseline value. The repeated variable was the time point. The covariance structure was specified as compound symmetry and degrees of freedoms were adjusted using Kenward-Rogers method.

The purpose of using a positive control (moxifloxacin) is to demonstrate that the study procedures are adequate to detect a placebo subtracted change from baseline $(\Delta \Delta \mathrm{QTc})$ effect of $5 \mathrm{~ms}$. This is substantiated if the lower bound of the two-sided $90 \%$ CIs around the mean $\Delta \Delta \mathrm{QTcF}$ between moxifloxacin and placebo (ie, the estimates for the differences in the treatment by hour interaction least squares means between moxifloxacin and placebo) excludes $5 \mathrm{~ms}$ and fit the usual time course associated with moxifloxacin induced QT prolongation..$^{21,22}$

\section{Results}

\section{Diurnal variation of QTcF measurements} at baseline day

The diurnal variation, shown as the mean QTcF during the 24 hours of Day 1 (baseline day) of each period are presented in Figure 2. The mean QTcF at all time points were similar in all five periods, with a maximum noted in the mid-morning ( $\sim 1000$ hours) and a minimum noted during late afternoon (1800 hours). This diurnal change exceeded the threshold for a positive TQTS (5 ms).

\section{QTcF changes induced by moxifloxacin}

The estimates of $\Delta \Delta \mathrm{QTcF}$ (baseline adjusted change from placebo) and the associated $90 \%$ two-sided CIs are presented in Table 1 and Figure 3. The maximum changes in moxifloxacin induced QTcF were identified at 1 hour using any of the four baselines and the estimates of maximum mean change were quite similar $\left(\mathrm{TM}_{\mathrm{EACH}}+19.9 \mathrm{~ms}, \mathrm{TM}_{\mathrm{MEAN}}+20.0 \mathrm{~ms}\right.$, $\mathrm{TM}_{\mathrm{P} 1}+20.2 \mathrm{~ms}$, and $\mathrm{PD}_{\mathrm{EACH}}+20.7 \mathrm{~ms}$ ). Furthermore, the moxifloxacin induced QTcF prolongation was detected from 0.5 to 12 hours postdose using all four baselines: lower confidence limit (LCL) excluded $5 \mathrm{~ms}$.

\section{Variability associated with different baselines}

Estimates of variability of each baseline are shown in Table 2 as between and within subject standard deviations (SDs). The within subject SDs were $\mathrm{TM}_{\mathrm{EACH}} 5.59 \mathrm{~ms}, \mathrm{TM}_{\text {MEAN }} 5.90 \mathrm{~ms}$, $\mathrm{TM}_{\mathrm{P} 1} 6.90 \mathrm{~ms}$, and $\mathrm{PD}_{\text {EACH }} 7.41 \mathrm{~ms}$.

The between subject variability was largest with the $\mathrm{TM}_{\mathrm{EACH}}$ baseline, slightly smaller with the $\mathrm{TM}_{\mathrm{P} 1}$ baseline, and smallest with the $\mathrm{TM}_{\mathrm{MEAN}}$ or $\mathrm{PD}_{\mathrm{EACH}}$ baselines.

\section{Discussion}

ICH E14 guidance states that the propensity of any new drug to increase the QT interval needs to be assessed and should be baseline corrected. The primary endpoint of this study is not the maximum QT/QTc change but the limits of the CI associated with this change. Consequently, choice of TQTS design should consider the impact of baseline method on QT interval variability.

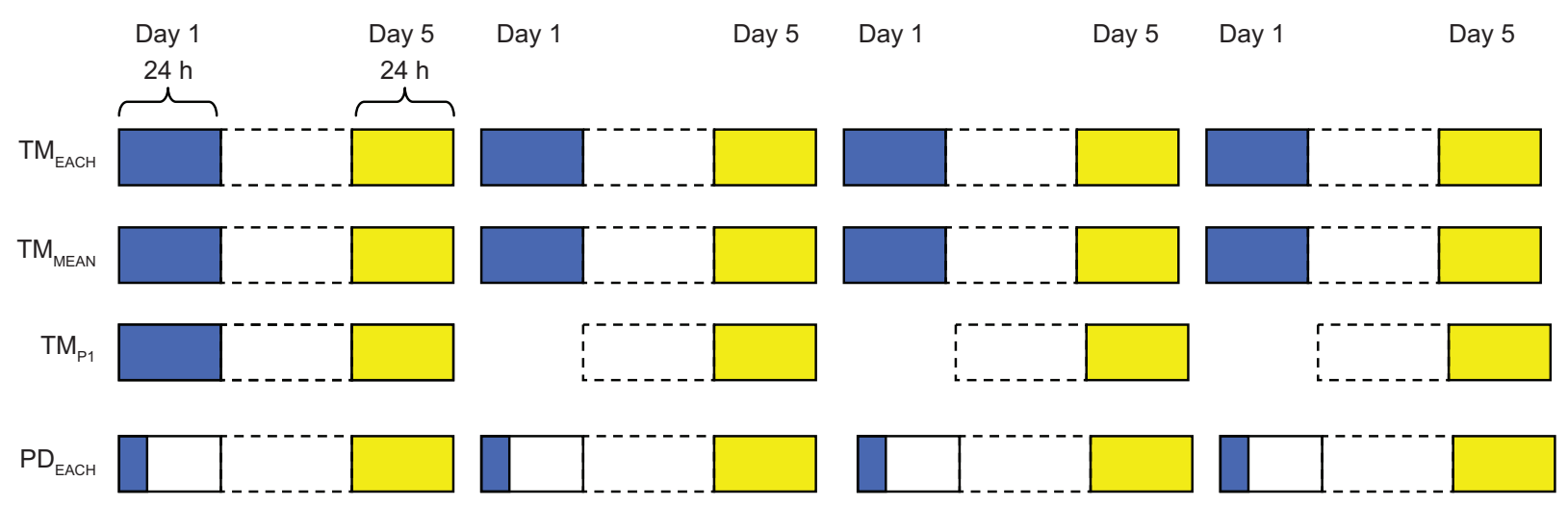

Figure I Description of the four baseline methods.

Notes: Blue: baseline ECG recording, full rectangle, 24 hours recording; partially empty rectangle, single time-point recording. Yellow: On drug ECG recording. 


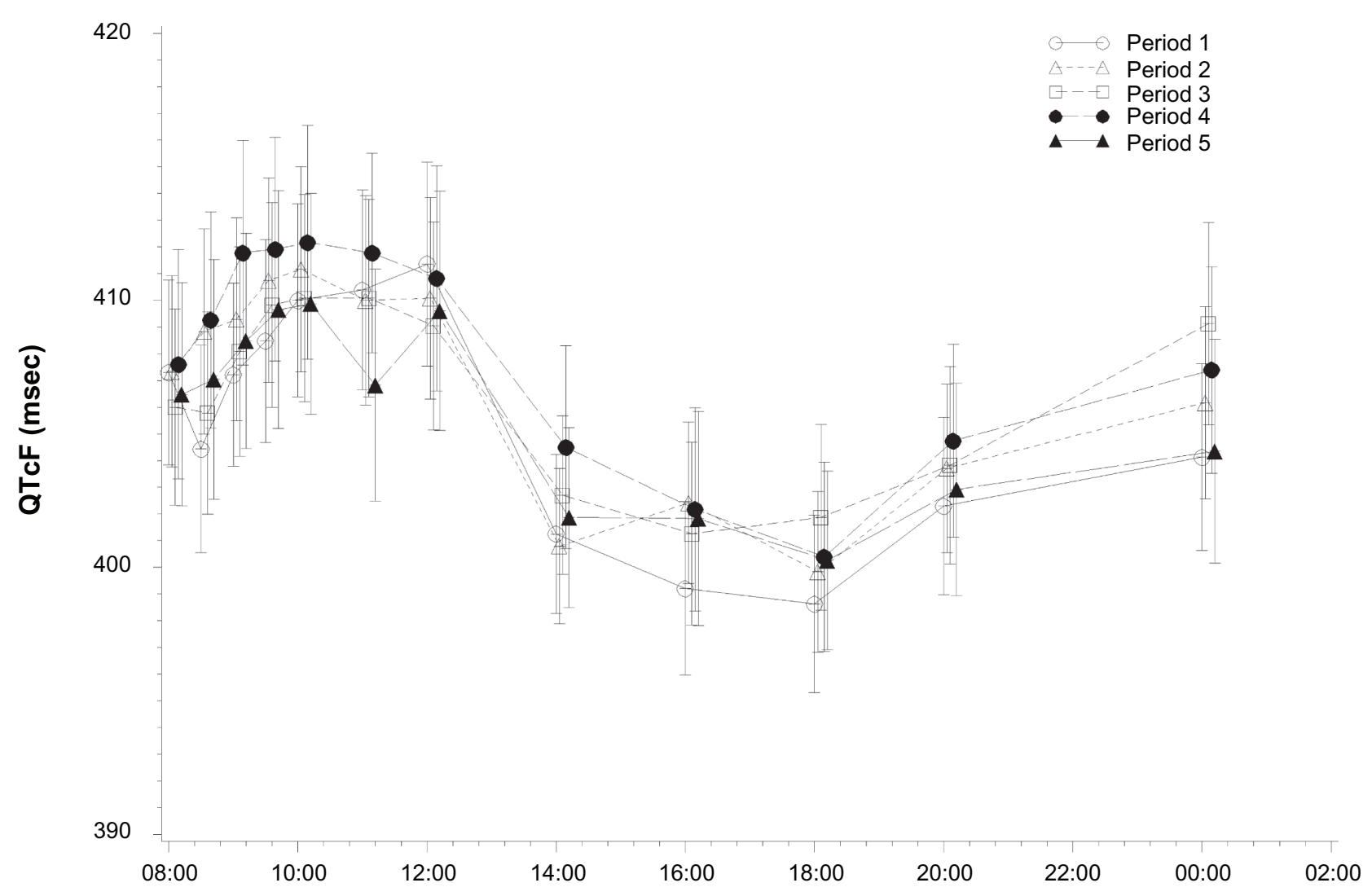

Clock time

Figure $2 \mathrm{QTcF}$ (Mean $\pm \mathrm{SE}$ ) recorded during the five baseline days.

Abbreviations: QTcF, QT Fridericia's correction. SE, standard error.

Table I Estimate placebo-corrected change from time-matched baseline QTcF with associated $90 \%$ two-sided confidence intervals

\begin{tabular}{|c|c|c|c|c|c|c|c|c|c|c|c|c|c|}
\hline \multicolumn{2}{|c|}{ Time point } & \multicolumn{3}{|c|}{$\begin{array}{l}24 \text { hour, each period } \\
\text { (TM each) }\end{array}$} & \multicolumn{3}{|c|}{$\begin{array}{l}\text { Mean of } 24 \text { hour } \\
\text { (TM mean) }\end{array}$} & \multicolumn{3}{|c|}{$\begin{array}{l}\text { Ist Period } \\
\text { (TM PI) }\end{array}$} & \multicolumn{3}{|c|}{$\begin{array}{l}\text { Predose, each } \\
\text { period (PD each) }\end{array}$} \\
\hline Day & Hour & Diff & LCL & UCL & Diff & LCL & UCL & Diff & LCL & UCL & Diff & LCL & UCL \\
\hline 4 & 0.0 & 7.5 & 4.59 & 10.41 & 7.3 & 4.25 & 10.38 & 7.8 & 4.18 & 11.42 & 7.9 & 4.06 & 11.76 \\
\hline 4 & 0.5 & 15.7 & 12.83 & 18.66 & 16.2 & 13.18 & 19.31 & 16.1 & 12.44 & 19.69 & 17.5 & 13.64 & 21.34 \\
\hline 4 & 1.0 & 19.9 & 16.99 & 22.81 & 20.0 & 16.89 & 23.02 & 20.2 & 16.62 & 23.86 & 20.7 & 16.83 & 24.53 \\
\hline 4 & 1.5 & 17.9 & 14.97 & 20.79 & 18.1 & 15.07 & 21.20 & 18.3 & 14.65 & 21.89 & 19.1 & 15.29 & 22.99 \\
\hline 4 & 2.0 & 17.8 & 14.88 & 20.70 & 17.8 & $|4.7|$ & 20.84 & 17.5 & 13.86 & 21.10 & 18.4 & 14.50 & 22.21 \\
\hline 4 & 3.0 & 18.9 & 15.94 & 21.81 & 18.7 & 15.62 & 21.81 & 18.8 & 15.17 & 22.48 & 19.2 & 15.28 & 23.05 \\
\hline 4 & 4.0 & 19.3 & 16.33 & 22.26 & 19.1 & 16.02 & 22.27 & 18.8 & 15.05 & 22.50 & 20.7 & 16.75 & 24.59 \\
\hline 4 & 6.0 & 11.7 & 8.76 & 14.58 & II.I & 8.00 & 14.14 & II.I & 7.55 & 14.73 & 11.0 & 7.14 & 14.92 \\
\hline 4 & 8.0 & 14.0 & 11.14 & 16.91 & 13.7 & 10.69 & 16.76 & 13.7 & 10.17 & 17.29 & 13.8 & 9.92 & 17.63 \\
\hline 4 & 10.0 & 9.3 & 6.43 & 12.20 & 9.3 & 6.30 & 12.37 & 9.3 & 5.77 & 12.88 & 10.2 & 6.36 & 14.07 \\
\hline 4 & 12.0 & 9.5 & 6.62 & 12.39 & 9.5 & 6.50 & 12.58 & 9.5 & 5.98 & 13.09 & 10.4 & 6.60 & 14.30 \\
\hline 4 & 16.0 & 7.5 & 4.61 & 10.38 & 7.6 & 4.53 & 10.60 & 7.6 & 4.00 & 11.11 & 8.2 & 4.38 & 12.08 \\
\hline 5 & 24.0 & 6.9 & 3.95 & 9.77 & 6.7 & 3.62 & 9.75 & 7.3 & 3.64 & 10.88 & 7.3 & 3.42 & 11.13 \\
\hline 5 & 36.0 & 0.1 & -2.82 & 2.94 & 0.1 & -2.95 & 3.13 & 0.1 & -3.47 & 3.64 & 1.3 & -2.52 & 5.18 \\
\hline 6 & 48.0 & 0.4 & -2.50 & 3.32 & 0.2 & -2.84 & 3.29 & 0.3 & -3.32 & 3.92 & 0.8 & -3.03 & 4.67 \\
\hline 7 & 72.0 & -3.2 & -6.08 & -0.26 & -3.3 & $-6.4 I$ & -0.28 & -3.1 & -6.75 & 0.49 & -2.8 & -6.61 & 1.10 \\
\hline
\end{tabular}

Abbreviations: TM, time-matched baseline; PD, predose baseline; QTcF, QT Fridericia's correction; Diff, difference (ms) between Moxifloxacin and placebo; LCL, lower bound of the confidence interval (ms); UCL, upper bound of the confidence interval (ms). 


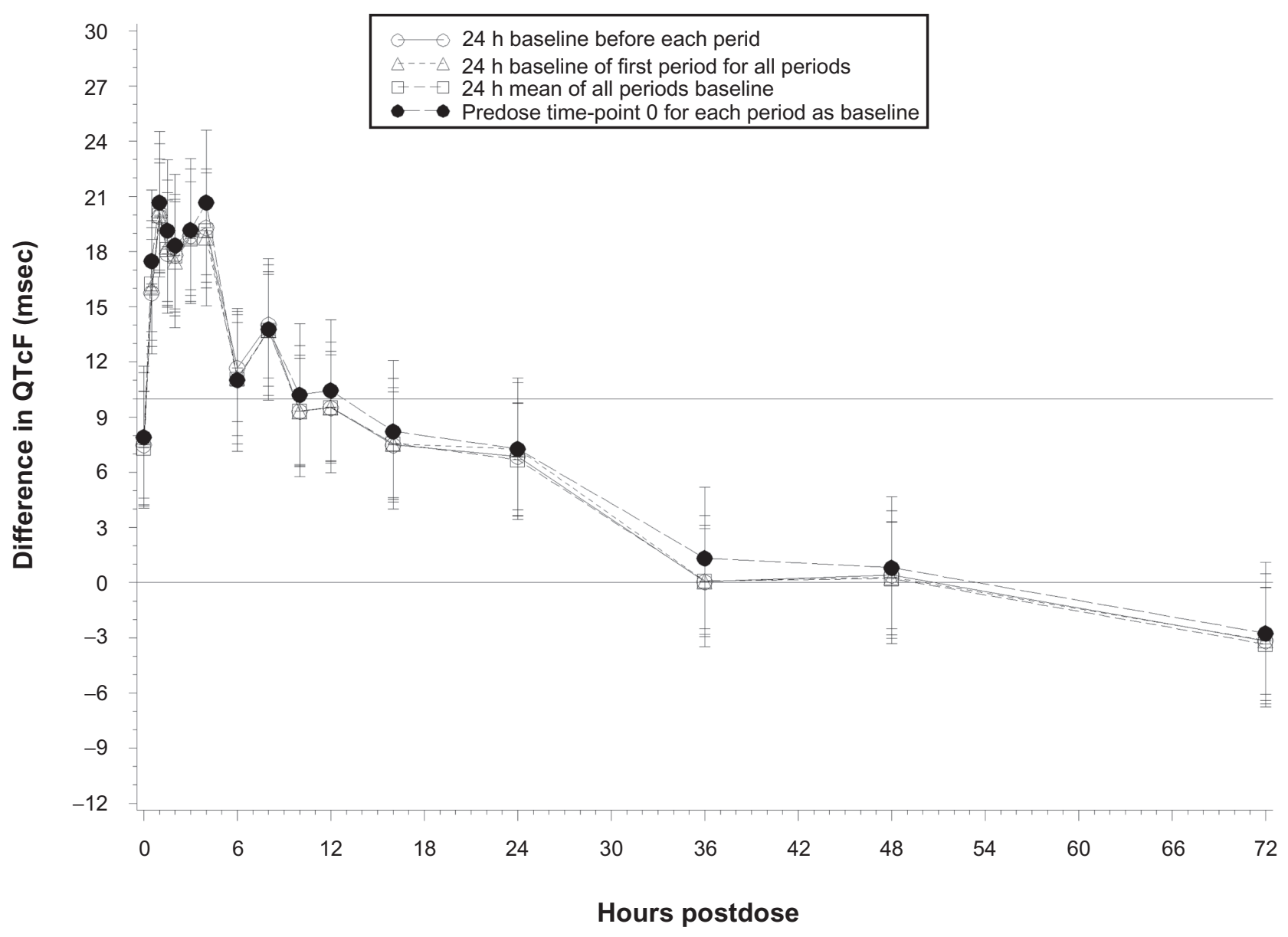

Figure $3 \Delta \Delta \mathrm{QTcF}$ and associated $90 \%$ two-sided confidence intervals after moxifloxacin administration. Abbreviations: $\Delta \Delta \mathrm{QTCF}$, baseline adjusted change from placebo; h, hours.

Because QTcF is affected by the time of day, ${ }^{7-9}$ subject activity, and autonomic tone changes, ${ }^{23,24}$ the collection of multiple ECG recordings prior to dosing is recommended. To analyze the effect of treatment on QTcF prolongation, the baseline has to be defined and the change from baseline $(\triangle \mathrm{QTCF})$ for each subject has to be calculated. The $\triangle \mathrm{QTcF}$ is then subjected to an ANCOVA where the baseline value is included as a covariate in order to improve the precision of the treatment comparisons. The EMEA, CPMP/EWP/2863/9925 recommends that whether the actual outcome $(\mathrm{QTc})$ or change from baseline variable $(\Delta \mathrm{QTc})$ is used in the analysis, the baseline value should be included as a covariate.

Senn ${ }^{26}$ discussed the issue of subtracting the corresponding baseline from the associated outcome value before analysis (ie analyzing $\Delta \mathrm{QTcF}$ in our study) and stressed that if the baselines were not strongly predictive of the outcome, then the variability of the resulting estimator $(\triangle \mathrm{QTcF})$ would be increased. This has implications for the choice of a time-matched or a predose baseline. If there were no evidence of any diurnal pattern in the QTcF changes, then using a predose baseline would result in higher precision of the estimator. In addition, because of day to day QT variability, a predose baseline may reduce the variability in a single dose study, especially if $\mathrm{T}_{\text {max }}$ is expected within a few hours postdose.

Table 2 Within- and between-subject standard deviations (SD)

\begin{tabular}{|c|c|c|}
\hline \multirow[t]{2}{*}{ Baseline } & \multicolumn{2}{|l|}{ QTcF } \\
\hline & $\begin{array}{l}\text { Within-subject } \\
\text { SD (ms) }\end{array}$ & $\begin{array}{l}\text { Between-subject } \\
\text { SD }\end{array}$ \\
\hline $\begin{array}{l}24 \text { hour, each } \\
\text { period }\left(\mathrm{TM}_{\mathrm{EACH}}\right)\end{array}$ & 5.59 & 9.61 \\
\hline $\begin{array}{l}24 \text { hour, mean of all } \\
\text { periods }\left(\mathrm{TM}_{\text {MEAN }}\right)\end{array}$ & 5.90 & 3.13 \\
\hline $\begin{array}{l}24 \text { hour, Ist period } \\
\left(\mathrm{TM}_{\mathrm{PI}}\right)\end{array}$ & 6.90 & 5.71 \\
\hline $\begin{array}{l}\text { Predose, each } \\
\text { period }\left(\mathrm{PD}_{\mathrm{EACH}}\right)\end{array}$ & $7.4 I$ & 3.50 \\
\hline
\end{tabular}

Abbreviations: TM, time-matched baseline. PD, predose baseline. SD, standard deviation. 
The E14 guidance recommends a positive control to show that the study is able to detect a $5 \mathrm{~ms}$ mean QT/QTc difference between the positive control and placebo as demonstrated by the LCL excluding $5 \mathrm{~ms}$ (for moxifloxacin). ${ }^{6-22} \mathrm{In}$ this study, the LCL of the $\Delta \Delta \mathrm{QTCF}$ between moxifloxacin and placebo excluded $5 \mathrm{~ms}$ at all time points from 0.5 hours to 12 hours post dose on Day 4, for all baseline alternatives.

The number of time points is a major determinant of the cost of a TQTS. Within subject SD was minimally smaller with $\mathrm{TM}_{\mathrm{EACH}}(5.59 \mathrm{~ms})$ than $\mathrm{TM}_{\text {MEAN }}(5.90 \mathrm{~ms})$. Both methods require time-matched baselines during each period and would result in the same cost with no gain in precision of treatment.

Collecting a single 24-hour baseline before the first period would reduce study cost. However, previous reports ${ }^{27}$ reveal the QT/RR relationship may not be stable over time for all individuals during TQTS. Because the same baseline QTcF values are subtracted from both the placebo and moxifloxacin QTcF outcomes, the expected $\Delta \Delta \mathrm{QTc}$ estimates are the same as if the baseline values were not subtracted. However, the baseline is still included as a covariate to reduce the within subject $\mathrm{SD}$. The results of this analysis demonstrated that the within subject SD was slightly larger $(6.90 \mathrm{~ms})$ than with the other time-matched baseline methods.

Using a single predose value for each period is the least costly alternative. But unlike previous baseline assessment reports in two single-dose studies, ${ }^{13,14}$ in this study $\mathrm{PD}_{\mathrm{EACH}}$ resulted in the largest within subject SD $(7.41 \mathrm{~ms})$. Day to day variability may explain this finding that supports a higher precision associated with the use of a full baseline day recording. However, it detected similar maximum moxifloxacin induced QTcF prolongation at the same time points as the three other baseline methods.

The within-subject variability is a main determinant of the sample size needed for a well designed TQTS. The sample size necessary to exclude a significant QT/QTc increase following ICH E14 criteria induced by a drug with an expected QTc increase of $2 \mathrm{~ms}$ at 5 time points varies from 16 subjects per arm (within subject $\mathrm{SD}=6 \mathrm{~ms}$ ) to 27 subjects per arm (within subject $\mathrm{SD}=8 \mathrm{~ms}$ ) with $85 \%$ power and $\alpha=0.05 .^{28}$ Therefore, the use of the predose method would require a slightly larger sample size.

In conclusion; in a multiple dose, crossover TQTS, the use of a $\mathrm{PD}_{\mathrm{EACH}}$ rather than a full 24-hour baseline may be more cost effective. Although full 24-hour baseline methods were associated with lower SD, the most cost effective design, $\mathrm{PD}_{\mathrm{EACH}}$, was still sufficient for detection of moxifloxacin induced QTcF prolongation in this multiple dose TQTS, despite a small sample size.

\section{Disclosures}

All authors were employees of MDS Pharma services at the time of the study and have no conflict of interest to disclose.

\section{References}

1. Dessertenne F. Ventricular tachycardia with 2 variable opposing foci. Arch Mal Coeur Vaiss. 1966;59(2):263-272.

2. Wang SH, Lin CY, Huang TY, Wu WS, Chen CC, Tsai SH. QT interval effects of cisapride in the clinical setting. Int $J$ Cardiol. 2001;80(2-3):179-183.

3. Roden DM. Drug-induced prolongation of the QT interval. $N$ Engl J Med. 2004;350(10):1013-1022.

4. Yap YG, Camm AJ. Drug induced QT prolongation and torsades de pointes. Heart. 2003;89(11):1363-1372.

5. Roden DM, Anderson ME. The pause that refreshes, or does it? Mechanisms in torsades de pointes. Heart. 2000;84(3):235-237.

6. ICH Topic E 14 The Clinical Evaluation of QT/QTc Interval Prolongation and Proarrhythmic Potential for Non-Antiarrhythmic Drugs. 2005; [Accessed September, 2009] Available from: http://www.emea.europa. eu/pdfs/human/ich/000204en.pdf.

7. Marfella R, Gualdiero P, Siniscalchi M, et al. Morning blood pressure peak, QT intervals, and sympathetic activity in hypertensive patients. Hypertension. 2003;41(2):237-243.

8. Yee KM, Pringle SD, Struthers AD. Circadian variation in the effects of aldosterone blockade on heart rate variability and QT dispersion in congestive heart failure. J Am Coll Cardiol. 2001;37(7):1800-1807.

9. Molnar J, Ranade V, Cvetanovic I, Molnar Z, Somberg JC. Evaluation of a 12-lead digital Holter system for 24-hour QT interval assessment. Cardiology. 2006;106(4):224-232.

10. Nagy D, DeMeersman R, Gallagher D, et al. QTc interval (cardiac repolarization): lengthening after meals. Obes Res. 1997;5(6):531-537.

11. Williams GC, Dunnington KM, Hu MY, et al. The impact of posture on cardiac repolarization: more than heart rate? J Cardiovasc Electrophysiol. 2006;17(4):352-358.

12. Health Canada Guidance Document. Guide for the Analysis and Review of QT/QTc Interval Data. [Accessed September 2009] Available from: http://www.hc-sc.gc.ca/dhp-mps/alt_formats/hpfb-dgpsa/pdf/ prodpharma/qt_review_examen-eng.pdf.

13. Bloomfield DM, Kost JT, Ghosh K, et al. The effect of moxifloxacin on QTc and implications for the design of thorough QT studies. Clin Pharmacol Ther. 2008;84(4):475-480.

14. Zhang X, Silkey M, Schumacher M, et al. Period correction of the QTc of moxifloxacin with multiple predose baseline ECGs is the least variable of 4 methods tested. J Clin Pharmacol. 2009;49(5):534-539.

15. Badilini F, Maison-Blanche P, Childers R, Coumel P. QT interval analysis on ambulatory electrocardiogram recordings: a selective beat averaging approach. Med Biol Eng Comput. 1999;37(1):71-79.

16. Kligfield P, Tyl B, Maarek M, Maison-Blanche P. Magnitude, mechanism, and reproducibility of QT interval differences between superimposed global and individual lead ECG complexes. Ann Noninvasive Electrocardiol. 2007;12(2):145-152.

17. Fridericia LS. The duration of systole in an electrocardiogram in normal humans and in patients with heart disease. 1920. Ann Noninvasive Electrocardiol. 2003;8(4):343-351.

18. Malik M, Farbom P, Batchvarov V, Hnatkova K, Camm AJ. Relation between QT and RR intervals is highly individual among healthy subjects: implications for heart rate correction of the QT interval. Heart. 2002;87(3):220-228.

19. Malik M, Hnatkova K, Batchvarov V, Gang Y, Smetana P, Camm AJ. Sample size, power calculations, and their implications for the cost of thorough studies of drug induced QT interval prolongation. Pacing Clin Electrophysiol. 2004;27(12):1659-1669.

20. Couderc JP, Xiaojuan X, Zareba W, Moss AJ. Assessment of the stability of the individual-based correction of QT interval for heart rate. Ann Noninvasive Electrocardiol. 2005;10(1):25-34. 
21. Garnett CE, Beasley N, Bhattaram VA, et al. Concentration-QT relationships play a key role in the evaluation of proarrhythmic risk during regulatory review. J Clin Pharmacol. 2008;48(1):13-18.

22. E14 Clinical Evaluation of QT/QTc Interval Prolongation and Proarrhythmic Potential for Non-Antiarrhythmic Drugs. Questions and Answers. 2008; [Accessed September 2009] Available at http://www. emea.europa.eu/pdfs/human/ich/31013308en.pdf.

23. Diedrich A, Jordan J, Shannon JR, Robertson D, Biaggioni I. Modulation of QT interval during autonomic nervous system blockade in humans. Circulation. 2002;106(17):2238-2243.

24. Ong JJ, Sarma JS, Venkataraman K, Levin SR, Singh BN. Circadian rhythmicity of heart rate and QTc interval in diabetic autonomic neuropathy: implications for the mechanism of sudden death. Am Heart J. 1993;125(3):744-752.
25. Journal article on the Internet: The European Agency for the Evaluation of Medicinal Products (EMEA), committee for Proprietary Medicinal Products (CPMP), Efficacy Working Party (EXP). Points to consider on adjustment for baseline covariates.[Accessed 2009]. http://www.emea. europa.eu/pdfs/human/ewp/286399en.pdf

26. Senn SJ. Cross-over trials in clinical research. 2nd ed. Chichester: Willey; 2002.

27. Extramiana F, Maison-Blanche P, Haggui A, Badilini F, Beaufils P, Leenhardt A. Control of rapid heart rate changes for electrocardiographic analysis: implications for thorough QT studies. Clin Cardiol. 2006;29(12):534-539.

28. Zhang J, Machado SG. Statistical issues including design and sample size calculation in thorough QT/QTe studies. J Biopharm Stat. 2008;18(3):451-467.

\section{Publish your work in this journal}

The Open Access Journal of Clinical Trials is an international, peerreviewed, open access journal publishing original research, reports, editorials, reviews and commentaries on all aspects of clinical tria design, management, legal, ethical and regulatory issues, case record form design, data collection, quality assurance and data auditing

\section{Dovepress}

methodologies. The manuscript management system is completely online and includes a very quick and fair peer-review system, which is all easy to use. Visit http://www.dovepress.com/testimonials.php to read real quotes from published authors.

Submit your manuscript here: http://www.dovepress.com/open-access-journal-of-clinical-trials-journal 